\title{
A Moving Target: The Problem of Defining Teacher Quality
}

\author{
By Deborah Zuercher * \\ Jon Yoshioka ${ }^{\dagger}$ \\ Joseph Zilliox ${ }^{*}$
}

With No Child Left Behind Legislation, the United States Department of Education defined a Highly Qualified Teacher as a teacher who has earned a bachelor degree, full state certification, and demonstrated competency as defined by the state in each core academic subject he or she teaches (USDOE, 2002). The Obama Blueprint for Education (USDOE, 2010) introduces the term Teacher Effectiveness, a measure that places emphasis on the assessment of student outcomes, but the Blueprint maintains the requirements for Highly Qualified Teacher. There is a problem of shifting and indistinct definitions of teacher quality. As educators, we are accustomed to the creation and use of rubrics to assess knowledge, skills, and dispositions of learners, yet a consistent U.S. Federal rubric to assess Teacher Quality or Teacher Effectiveness is lacking. It is a challenge for teacher educators to create on target professional development for pre-service or in-service teachers when the target keeps moving. Defining Teacher Effectiveness is particularly challenging in diverse multicultural teaching contexts with compounding issues such as English Language Learner (ELL) adaptations and culturally relevant pedagogy. This exploratory case study describes teachers' perceptions of Highly Qualified Teacher criteria and interventions that are being pilot tested to define and support Highly Effective teacher professional development in the Pacific.

\section{Introduction}

Recent developments in the field of education have brought the idea of teacher quality to the forefront of both the public and academic arenas. Two large-scale examples of this current push include the U.S. federal government's Race to the Top program which allotted $\$ 4.35$ billion for K-12 reform (Dillon \& Silva, 2011) and the efforts of nearly all countries in the Asia Pacific region to engage in educational reform to provide students with the skills needed to be

\footnotetext{
*Associate Professor, University of Hawai'i, USA.

${ }^{\dagger}$ Associate Professor, University of Hawai'i, USA.

tProfessor, University of Hawai'i, USA..
} 
successful in the knowledge-based global economy (Cheng \& Townsend, 2000).

While it is an indisputable fact that teacher quality is important in all facets of education, the characteristics of what make up a quality teacher are much less well defined (Mastekaasa, 2011). For example, the current focus on teacher accountability has given rise to the inclusion of value added measures in teacher evaluation instruments. While in theory it may sound like measuring a teacher's contribution to a student's success will be easy, doing so in real-life has proven to be problematic. In fact, a closer examination of the research reveals a key question for policy makers promoting this focus: Can valueadded measures, despite their shortcomings, be relied upon to provide valuable information when considering personnel decisions (Hanushek \& Rivkin, 2010) such as 'reward, remediation or removal' (Hill, Kapitula, \& Umland, 2011, p. 826)?

What, then, can be agreed upon? For one thing, quality teachers, those that are both highly qualified and highly effective, tend to be intellectually able, possessing a strong subject area background and a variety of pedagogical approaches to teach their content. They also are good communicators who possess strong verbal and presentation skills. They are adept at classroom management and are skilled assessors who can adapt their instruction to learner needs. Finally, they also work well in collaboration with others (Looney (2011). These characteristics, however, tell only part of the story.

Quality teachers are the single most important factor affecting student achievement (Education Commission of the States, 2003; Sanders \& Rivers, 1996). Content Area Specialized Teacher (CAST) facilitators recognized this and focused their efforts on creating a professional development (PD) model that would develop a local population of teachers into effective teacher leaders. Within this framework, teacher buy-in was essential in developing quality teachers who actively believed in and practiced reform. The 2007 United Nations Educational, Scientific and Cultural Organization (UNESCO) International institute for Educational Planning report supports this view, stating that no reform measure can be effective without the active support of teachers. 'The teacher is at the epicenter of the learning process; and learning therefore depends first and foremost on the quality of the teacher' (Schwille \& Dembele, 2007, p.15). There is general agreement that continuous training and $\mathrm{PD}$ in the areas of content knowledge and the teacher's competence in transmitting this knowledge to different students are essential for improved academic performance across global classrooms (Henard, 2010).

With this in mind, CAST facilitators focused on two main goals in supporting and developing highly effective quality teachers. The first goal was to design, initiate, implement, and manage an effective PD program for grades K-12 teacher leaders that would (a) strengthen content knowledge in Language Arts, Mathematics, Science and Social Studies, and (b) enhance pedagogical content knowledge and skills for instructional support.

The CAST project's second goal was to create an environment of 'critical mass', where local teachers could create and maintain a self-sustaining 
atmosphere of positive change by designing, initiating, implementing, and managing an effective PD program for teacher leaders. CAST facilitators helped the practicing K-12 teacher leaders develop the skills and dispositions needed to deliver PD opportunities to their colleagues across the K-12 spectrum including Language Arts, Mathematics, Science and Social Studies. The CAST facilitators believed that the local educational professionals taking part in the PD had the content expertise and pedagogical knowledge and skills to most effectively teach in their unique cultural milieu and respectfully returned curriculum and instruction decisions to them over the course of and at the end of the PD sessions.

\section{Background}

Guam and American Samoa may initially appear to be strikingly similar in terms of both location and population. They are islands, located in the Pacific, with warm weather and a predominantly local population. However, a closer examination reveals that the two islands are actually $5800 \mathrm{~km}$ (3600 miles) apart, and each has a unique cultural climate that needs to be understood in order to successfully work with the local teaching population. In order to build an effective relationship with the teachers in Guam and American Samoa, it was imperative to consider the cultural issues of each place. For example, due to the distance each island is from the continental U.S., conducting PD using a $100 \%$ online format would seem to be the most cost effective and efficient way to do things, unless one realizes that not all of the teachers may have access to reliable internet connections every day, or that face-to-face communication with their instructors is extremely important to teachers in both places (Ho \& Burniske, 2005).

One of the main things that tie these two islands together is the influence that the U.S. educational system reform movements and U.S educational policies have had on their respective school systems. Since the 1980's, these educational reform movements have focused on excellence, restructuring, standards, and accountability (Hunt, 2008).

\section{Education Reform in the Territory of Guam and in the Territory of American Samoa}

The Territory of Guam is the largest island in Micronesia, located in the western Pacific Ocean, the island was taken from Spain by the United States during the Spanish American War in 1898 and since that time, the U.S. has had a military presence there. This U.S. presence has had a profound impact. For example, the planned move of 5000 U.S. marines to Guam during the upcoming years is expected to cause a dramatic population increase that will significantly impact changes in education and infrastructure (Kan, 2012). Consequently, U.S. education reform movements predominantly influence the public school system in the Territory of Guam. 
The organization of the American Samoan school system is similar to Guam in that it exists in and interacts with a larger social system of politics, economics, and culture that has also been influenced by over 100 years of affiliation with U.S. educational philosophy and values (Allen, 1962). American Samoa, like Guam, has a unique political status as an "unorganized and unincorporated" United States' Territory whose residents are U.S. "nationals" who cannot vote in national elections in the United States and have no representation in the final approval of legislation by Congress (United States General Accounting Office, 1997, p. 9).

As a South Pacific nation, American Samoa has its own unique Samoan language and culture. Yet, the history of public schooling and teacher education in American Samoa is closely linked to the American colonization of the American Samoa Territory. The first public school was established in American Samoa in 1904 with naval wives and officers serving as teachers (Sutherland, 1941). This set in motion four distinct phases of development of teacher education in American Samoa: (a) Phase I: The United States Navy Administration (1904-1952), (b) Phase II: The Barstow Foundation Efforts (1932-1960), (c) Phase III: The Educational Television ETV Era (1962-1971), and (d) Phase IV: The Samoanization Movement (1972-1986) (Reid, 1986, p. 20). Earlier phases were characterized by systems based on the American school model that were imposed on Samoan teachers without regard to cultural context. The resulting conflicts, stemming from a lack of cultural understanding, were gradually understood and now, in what could be termed, Phase V: The University of Hawai'i Transnational Partnership Era (19792011), a successful transnational partnership has been successfully established and cultivated over the past 30 years.

At the time of the CAST PD, both Guam and American Samoa teachers relied on primarily Direct Instructional techniques in their classrooms. This technique ran counter to the collectivist nature of both places where family, community, and societal bonds often superseded the more individualistic views of Western cultures. Recognizing this, the CAST facilitators planned and introduced a variety of collaborative, hands-on, constructivist techniques and methodologies in their sessions that fit more closely with the strong sense of community that was prevalent in both island cultures.

\section{Methodology}

\section{Demographics}

Both the Guam Public School System (GPSS) and the American Samoa Department of Education (ASDOE) are single unified school districts. The GPSS consists of twenty-seven elementary schools, eight middle schools, five high schools and one alternative school that serve over 30,000 students, while the ASDOE consists of 24 Early Childhood Education centers, 23 elementary schools, and 6 high schools serving over 14,150 students. 
The CAST-Guam (CAST-G) team, comprised of five content area specialists, was recruited by the University of Guam (UOG) to provide PD to 29 CAST-G teachers in science, social studies, English/Language arts, and mathematics. CAST-G teachers ranged in age from 20-70 years old, with the majority (83\%) falling in the 31-60 year-old range. CAST-G teachers' experience ranged from 0-35 years, with no less than two and no more than five teachers being part of any five-year grouping. With respect to content areas, $43 \%$ of CAST-G teachers taught science, $32 \%$ taught math, $17 \%$ taught social studies, and $9 \%$ taught language arts.

The CAST-American Samoa (CAST-AS) team was also comprised of five content area specialists, who were recruited by the ASDOE to provide PD to 71 CAST-AS teachers in science, social studies, English/Language arts, and mathematics. CAST-AS teachers ranged in age from 20-60 years old, with the majority $(85 \%)$ falling in the 31-60 year-old range. CAST-AS teachers' experience ranged from 0-35 years, with the most teachers having between 610 years of experience. With respect to content areas, 32\% of CAST-AS teachers taught math, while $25 \%$ taught Language Arts, $25 \%$ taught science, and $18 \%$ taught social studies.

\section{Procedure}

The CAST-G and CAST-AS PD sessions involved a face-to-face eight day session in July with three days of planning with the CAST instructors and five days with two 90 minute Content and Pedagogy sessions and one 90 minute leadership session each day. CAST participants were surveyed throughout the project to determine their impressions of the PD.

Each CAST consultant employed three methods of data collection during their sessions: (a) Unstructured group interviews, where participants were asked to describe their experience as a cohort member in a free flowing discussion format and CAST facilitators listened to the responses and asked probing questions to gain a deeper understanding of the participant's views of the PD sessions, (b) Participant observation, where participants were observed during the PD sessions to determine: (a) how they applied the new instruction, (b) what parts of the instruction they were having problems with, and (c) what parts of instruction they could most easily apply in their classrooms. CAST consultants noted similar and dissimilar events for use in the coding process, and (c) Semi-structured group interviews with open-ended questions, where participants were asked during each training session for their feedback on the sessions: (a) what they liked, (b) what they found useful, (c) what could be applied in their classes, and (d) what they would like more instruction on. CAST consultants listened to the responses and asked clarifying questions if responses were unclear or incomplete.

The following two methods were used at the end of the PD sessions: (a) Focus groups, where the content area groups were brought together to discuss the strengths and weaknesses of the PD sessions. CAST consultants listened to the responses, took notes, and moderated the discussion as the content area 
participants were encouraged to freely express their opinions and offer detailed responses to the questions asked. and (b) Questionnaires, which CAST facilitators administered to determine what areas of the PD were beneficial and what needed to be improved upon. The raw data from each survey was examined and problematic data such as incomplete responses (e.g., survey not fully completed) or questionable entries (e.g., inconsistent responses) were removed from the sample.

\section{Analysis of the Data}

A descriptive method was used to analyze the data. Visual representations including charts and simple statistical measures were used to obtain a feel for how the respondents viewed the PD sessions. Written responses to the surveys, verbal responses in interviews, and responses recorded via field notes were recorded verbatim.

\section{Coding}

CAST instructors used a grounded theory approach to code the open-ended data (Strauss \& Corbin, 1990). All CAST-G and CAST-AS participant responses were read and re-read by two CAST instructors who independently discovered the properties associated with the data. CAST instructors then shared their notes with each other, discussed their findings, and negotiated the mutually agreed upon findings.

CAST instructors used open coding to identify and categorize the relationships described by the data by focusing on the question "What are the perspectives of the CAST members on their perceived PD needs and their satisfaction with the CAST workshops" as the lens through which they examined the open-ended survey responses and textual material. As relationships in the data emerged, CAST instructors used axial coding to determine how these relationships related to a general framework. The final step in the coding process involved selective coding, where the CAST instructors examined all of the themes that emerged from the data and determined the core theme that best represented all of the data.

The core theme that emerged from the data was that while the PD sessions were deemed to be valuable for both CAST-G (96\%) and CAST-AS (100\%) participants, there was still a need for even more content area instruction and strategies that can be applied in their classrooms and for PD. The general themes that emerged from CAST-G and CAST-AS analysis can be found in the Results section.

\section{Data Triangulation}

The data was triangulated by: (1) Investigator triangulation, where multiple CAST instructors observed and analyzed the data at every phase of the process, sharing their findings and negotiating the final outcomes; and (2) Methodological triangulation, where multiple methods: (a) Unstructured group interviews, (b) Participant observation, (c) Semi-structured group interviews with open questions, (d) Focus Groups, and (e) Questionnaires, were used to 
collect the data.

\section{Results}

\section{Likert-type Scale Responses}

The survey contained five items that asked CAST-G and CAST-AS participants to circle the response that described (a) how ready they feel to begin offering PD, (b) how closely the content of CAST aligned to the standards, (c) if their participation in CAST met their expectations, (d) how likely were they to share the ideas gained through CAST participation with others, and (e) how useful were the CAST ideas, content, and strategies in their future PD as teachers.

Responses to the first question, "How ready do you feel to begin offering PD to your colleagues?" revealed that $63 \%$ of CAST-G and $90 \%$ of CAST-AS participants felt "Very Ready" or "Ready" to begin offering PD to their colleagues. Only $12 \%$ of CAST-G and $2 \%$ of CAST-AS participants felt unsure (either "Somewhat Ready" or "Not at all") about offering PD.

For the second question, "How closely was the content of CAST aligned to the standards?", 79\% of CAST-G and 98\% of CAST-AS participants reported that the PD sessions were "Very Closely" or "Closely" tied to the standards, while no one in either CAST-G or CAST-AS selected "Mostly Not At All" or "Not At All".

For the third question, "Did participation in CAST meet your expectations meet your expectations?", 92\% of CAST-G and $100 \%$ of CAST-AS participants indicated that participation in CAST was "Very Useful" or "Useful", while no one in either CAST-G or CAST-AS selected "Mostly Not At All" or "Not At All".

For the fourth question, "How likely are you to share ideas you gained through CAST participation with others?", 96\% of CAST-G and $95 \%$ of CAST-AS participants responded that they were "Very Likely" or "Likely" to share their new ideas with their fellow teachers. Only $4 \%$ of CAST-G and $4 \%$ of CAST-AS participants selected "Neutral" or "Not At All".

For the final question, "How useful are the CAST ideas, content, and strategies in your future PD as teachers?", 96\% of CAST-G and $100 \%$ of CAST-AS participants rated the PD as being "Very Useful" or "Useful", with no one in "CAST-G or CAST-AS selecting "Mostly Not At All" or "Not At All”.

\section{Rank Order Responses}

The survey contained one question related to what participants would like to receive more training in. Participants were asked to rank, by priority, three choices for more training. The choices were content knowledge, instructional strategies, and leadership. The ranking was done with $1=$ most important, $2=$ somewhat important, and $3=$ least important. According to the responses, there 
was no clear majority in CAST-G or CAST-AS answers. However, both CAST-G and CAST-AS participants ranked Instructional Strategies as number one, Content Knowledge as number two, and Leadership as number three for future choices in training.

\section{Open-Ended Responses}

Question One: "Why did you choose to participate in CAST?" In both CAST-G and CAST-AS, the overwhelming reason that respondents chose to attend the PD sessions was for professional growth. Seventy-seven percent of CAST-G and 91\% of CAST-AS respondents listed teaching strategies, content knowledge, new ideas, hands-on activities, and becoming agents of change as the reasons they attended. A CAST-G math teacher with one year of teaching experience stated, "I was informed this would jump start my career as a professional." A CAST-AS science teacher with 10 years of teaching experience described the reason for attending as an opportunity "To learn more teaching strategies to help students. To network with other teachers, especially the presenters, in making them resources for my teaching journey." Other reasons for attending included being personally invited and needing PD credits for certificate renewal.

Question Two: "What did you find most beneficial in CAST?" In both CAST-G and CAST-AS, the overwhelming choice for the most beneficial aspect of the PD was professional growth. Ninety-four percent of CAST-G and 98\% of CAST-AS respondents listed teaching strategies, content knowledge, new ideas, hands-on activities, interaction with instructors and colleagues and becoming agents of change as the reasons they attended. Other reasons for attending included encouragement from others and needing PD credits for certificate renewal.

Question Three: "What suggestions do you have for improving future CAST workshops?" In CAST-G $72 \%$ of respondents wanted even more strategies to teach their content. In CAST-AS $75 \%$ of respondents wanted more strategies to teach content or even longer workshop sessions.

Question Four: "Has your participation in CAST helped you feel more confident about offering PD to your colleagues? How has it helped?" In CAST-G $91 \%$ of respondents indicated an increased level of confidence when considering offering PD to colleagues. In CAST-AS 97\% of respondents indicated an increased level of confidence when considering offering PD to colleagues. A 15-year CAST-G science teacher stated, "yes it has, because I feel that being with the CAST has made me realize that there is so much that needs to be done for our teachers and our kids...there just aren't enough people who are committed to finally do something about improving our schools." A 12-year CAST-AS social studies teacher stated, "CAST has given me the opportunity to try out new methods and activities that I'm confident will make my teaching more effective. I also feel more confident about sharing what I've learned with colleagues."

Question Five: "What type of follow-up or support to the CAST workshop would be most useful to you?" Responses to this question varied considerably. 
For CAST-G, the responses, in order of most to least frequent, respondents asked for CAST to meet every year, more instructional strategies, technology integration, more help with implementing PD, feedback from instructors, sharing instructional strategies from other content areas, and constructive criticism from instructors. For CAST-AS, the responses, in order of most to least frequent, respondents asked for more instructional strategies, technology integration, feedback from instructors, more training and workshops, and sharing with colleagues.

Question Six: "Are you experiencing any frustrations in trying to implement positive changes within your work environment? Please explain." For both CAST-G and CAST-AS most participants indicated that they were not frustrated. However, of the CAST-G participants who said they are frustrated, four areas of difficulty emerged (a) time for PD, (b) funding for PD, (c) colleagues are resentful of PD or don't understand why they have to make changes, and (d) lack of support from their administrators. Of the CAST-AS participants who said they were frustrated, five areas of difficulty arose (a) a lack of access to materials and resources, (b) colleagues are resentful of PD or don't understand why they have to make changes, (c) problems with implementation, and (d) lack of support from their administrators.

\section{Discussion}

In regards to the first CAST goal, helping CAST-G and CAST-AS participants strengthen their content knowledge in language arts, math, science, and social studies, the data indicates that the four professional growth benefits of attending the CAST PD were: to (a) gain more effective teaching strategies, (b) increase participants' content area knowledge, (c) discover and share new ideas about how to present specific concepts, and (d) learn new hands-on activities were beneficial to $94 \%$ of CAST-G and $98 \%$ of CAST-AS participants. As one CAST-G science teacher with 15 years of teaching experience stated, "It was beneficial learning more strategies, ways of improving myself as a teacher, and gaining more confidence." Opinions were similar for CAST-AS participants, as a Language Arts teacher with 16 years of teaching experience indicated, "It has made me more comfortable using the strategies form these workshops to teach others."

However, the CAST-G participants also expressed the desire to have more content-based workshops. "Keep funding the cadre members. Seriously still would like training with more instructional strategies for my content area," was a comment given from a CAST-G social studies teacher with 28 years of teaching experience. CAST-AS participants also expressed the desire to have more workshops and even suggested extending the time of the workshops. A CAST-AS science teacher with 11 years of experience suggested that future CAST workshops "Should have a whole day in order for us to practice these hands-on materials" while a Science colleague with 20 years of teaching 
experience was more succinct stating that CAST PD should "Extend to three weeks." This desire for more or longer CAST-AS training sessions with an emphasis on content-based strategies was confirmed by $79 \%$ of the participants.

With respect to the second goal of CAST PD, to develop the skills and dispositions to deliver PD opportunities across the K-12 curriculum, the data indicates that the CAST project is well on its way to achieving this goal. After the initial CAST-G workshop, $87.5 \%$ of participants said they were likely to share the ideas they have learned with their peers. For the second CAST-G workshop, participants and instructors worked together to put on a PD workshop for GPSS teachers. CAST-G members mentioned that they would like more workshops offered with this format. After the initial CAST-AS workshop, 97\% of CAST-AS participants said that the workshop helped increase their confidence in delivering PD to their colleagues, while $95 \%$ said they would be very likely or likely to share the ideas they have learned.

\section{Recommendations}

CAST facilitators used feedback from the first CAST-G workshop to design the format for the second workshop. This needs-based focus worked extremely well. The second CAST-G workshop was eight days in length, with the first three days devoted to emphasizing additional instructional strategies for all content areas and content-specific planning time set aside for the implementation of a five-day PD workshop. CAST facilitators co-planned with CAST-G participants to develop content-specific strategies and pedagogy to share with other K-12 educators. The workshop was a resounding success with over 100 attendees. A second workshop held the following summer, planned entirely by CAST-G participants, was even more successful. This result was exactly what CAST facilitators envisioned, to create a self-sustaining group of local teachers trained to be able to successfully provide PD for their peers.

The successful CAST-G model was used to develop the CAST-AS PD workshop. Unfortunately, although the first CAST-AS workshop was a success, the second workshop, although approved, was not conducted due to changes in the political climate. This serves to reemphasize the need to consider the culture, politics, and economics of place and to remind us that changes can occur due to unforeseen circumstances.

The final recommendation was that CAST facilitators work with participants to find ways to build bridges between school administrators and the new ideas associated with this PD. Both CAST-G and CAST-AS participants suggested that time be set aside for representatives of the CAST initiative to meet with current school administrators and try to find ways to incorporate the goals of CAST into the upcoming school year. This final point is currently a work in progress, but there are signs that it has been effective. Many of the CAST-AS facilitators teach for UH Manoa's Territorial Teacher Apprenticeship Program (TTAP) in American Samoa and use the relationshipbased, culturally relevant approaches they used in the CAST program in their University classes. Through their efforts, the TTAP program has produced the 
last four Territorial Teachers of the Year, Iose Muasau (2012), Lita Timoteo (2011), Gingerlei Maga-Uili (2010), and Merweden Sulua (2009). The program also continues to consistently turn out highly qualified, effective teachers as evidenced by data taken from the 2010-2012 school years showing that an average of $88 \%$ of the Territory's District Teachers of the Year and $86 \%$ of the Territory's individual school's Teachers of the Year were graduates of the UH Manoa TTAP Program.

\section{References}

Allen, R. R. (1962). Developing a teacher education program at the Church College of Hawaii for students from American Samoa, Western Samoa and Tonga. Unpublished Doctoral Dissertation, University of Utah.

Cheng, Y. C. \& Townsend, T. (2000). Educational change and development in the Asia-Pacific region. In T. Townsend \& Y. C. Cheng (Eds.), Educational Change and Development in Asia-Pacific Region: Challenges for the Future (pp. 317344). The Netherlands: Swets \& Zeitlinger Publisher.

Dillon, E. \& Silva, E. (2011). Grading the teachers' teachers: Higher education comes under scrutiny. Phi Delta Kappan, 93(1): 54-58.

Education Commission of the States. (2003, August). Eight questions on teacher preparation: What does the research say? Denver, CO: ECS.

Hanushek, E. A. \& Rivkin, S. G. (2010). Using value-added measures of teacher quality. National Center for Analysis of Longitudinal Data in Education Research (CALDER). Urban Institute, Washington, D.C.

Henard, F. (2010). Learning our lesson: Review of quality teaching in higher education. Paris: OECD Publishing.

Hill, H., Kapitula, L., \& Umland, K. (2011). A validity argument approach to evaluating teacher value-added scores. American Educational Research Journal, 48(3): 794-831.

Ho, C. P. \& Burniske, R. W. (2005). The evolution of a hybrid classroom: Introducing online learning to educators in American Samoa. TechTrends, 49(1), 24-29.

Hunt, J. W. (2008). A Nation at Risk and No child Left Behind: Déjà vu for administrators? Phi Delta Kappan, 4, 580-585.

Kan, S. (2012). Guam: U.S. defense deployments. Congressional Research Service.

Looney, J. (2011). Developing high-quality teachers: Teacher evaluation for improvement. European Journal of Education, 46(4), 440-455.

Mastekaasa, A. (2011). Brain drain? Recruitment and retention of high quality teachers in Norway. Oxford Review of Education, 37(1): 53-74.

Reid, S. H. (1986). Educator's perceptions of the teacher education program goals and the educational needs of the territory of American Samoa. Unpublished doctoral dissertation. University of Hawaii.

Sanders, W.L. \& Rivers, J.C. (1996). Cumulative and residual effects of teachers on future student academic achievement. Knoxville: University of Tennessee ValueAdded Research and Assessment Center.

Schwille, J. \& Dembele, M. (2007). Global perspectives on teaching and learning: improving policy and practice. Paris, France: UNESCO.

Strauss, A., \& Corbin, J. (1990). Basics of qualitative research: Grounded theory procedures and techniques. Newbury Park, CA: Sage Publications. 
Sutherland, M. N. (1941). A study of teacher training in American Samoa. Unpublished master thesis, University of Hawaii.

United States Department of Education. (2010). A blueprint for reform: The reauthorization of the elementary and secondary education act. Retrieved January 10, 2013 from http://www2.ed.gov/policy/elsec/leg/blueprint/.

United States Department of Education. (2004). No child left behind: A toolkit for teachers (updated). Retrieved January 8, 2013 from www.ed.gov/teachers/ nclbguide/nclb-teachers-toolkit.pdf.

United States General Accounting Office. (1997). General accounting report to the Chairman Committee on Resources, House of Representatives. United States insular areas: Applications of the U.S. constitution. Washington, DC: United States General Accounting Office. 